\title{
Tribute to John L. Cameron, M.D.
}

\author{
Jeffrey B. Matthews • Charles J. Yeo
}

Received: 25 May 2011 /Accepted: 25 May 2011 / Published online: 4 June 2011

(C) 2011 The Society for Surgery of the Alimentary Tract

Dr. John L. Cameron has been involved with every issue of the Journal of Gastrointestinal Surgery since it was founded in 1997. Together with Co-Editor Dr. Keith A. Kelly (now emeritus), Dr. Cameron brought the journal from a quarterly publication to one that is published monthly and now receives over 1,200 submissions annually. This month, as he transitions from his role as Editor in Chief, Dr. Cameron, along with Dr. Kelly, will be listed on our new masthead as our Founding Editors. We, the new co-editors of the journal, would like to recognize and honor Dr. Cameron's remarkable achievements.

Dr. Cameron was born and raised in Michigan. He received his undergraduate degree from Harvard University in 1958 and his medical degree from the Johns Hopkins University School of Medicine in 1962. After completing his medical studies, Dr. Cameron completed all of his surgical training at the Johns Hopkins Hospital. In 1971, he was appointed Assistant Professor of Surgery at Johns Hopkins. He was promoted to Associate Professor in 1974 and to full Professor in 1978. He was the recipient of numerous NIH grants studying gastrointestinal physiology and focusing on pancreatitis. In 1984, he was named Surgeon-in-Chief of the Johns Hopkins Hospital and Chairman of the Department of Surgery in the Johns Hopkins University School of Medicine. After a 19-year

\footnotetext{
J. B. Matthews

University of Chicago,

Chicago, IL 60637, USA

e-mail: jmatthews@uchicago.edu

C. J. Yeo $(\bowtie)$

Thomas Jefferson University,

Philadelphia, PA 19107, USA

e-mail: charles.yeo@jefferson.edu
}

tenure, in 2003, Dr. Cameron stepped down from his position as Surgeon-in-Chief to assume the position of the Alfred Blalock Distinguished Service Professor. Dr. Cameron remains active as a clinical surgeon, operating 5 days a week, as a teacher, and as an investigator. His career at Johns Hopkins now spans a 53-year period.

Throughout his career, Dr. Cameron's interests have primarily been focused in the field of alimentary tract surgery. He has made many contributions to the understanding of the pathophysiology and management of a variety of benign and malignant pancreatic diseases. He was an early investigator in the field of acute pancreatitis, and his name is most often associated with the Whipple procedure, a complex operation used to treat a variety of pancreatic diseases, including pancreatic cancer. He has performed more of these Whipple operations than any other surgeon in the world. Dr. Cameron has been a member of many of the most important surgical associations and societies in the USA and has served as the President of the Halsted Society, the Society for Surgery of the Alimentary Tract, the Society for Clinical Surgery, the Society for Surgical Chairs, the Southern Surgical Association, the American Surgical Association, and the American College of Surgeons.

Dr. Cameron has published well over 450 articles and over 100 book chapters, and he is the editor of 20 books. He has been on the editorial boards of many journals and still serves as the editor of Advances of Surgery and coeditor of Current Surgical Therapy (now in its 10th edition).

Under Dr. Cameron's supervision, the Journal of Gastrointestinal Surgery has become one of the premier international journals in the field of alimentary tract surgery. The journal's impact factor has continued to rise, and its editorial board now spans many continents and includes 
prominent alimentary tract surgeons from around the world. Dr. Cameron has proven to be a remarkable mentor to many and, particularly, to us, the rising new co-editors of the Journal of Gastrointestinal Surgery. We appreciate the guidance he has given us over the last 4 years as associate co-editors, and we hope that we will be able to continue to call on him for advice. We are grateful for the energy and leadership that Drs. Cameron and Kelly provided during the time that this journal was in its early days. We only hope that we can carry on their tradition and continue to strengthen the journal and its affiliation with the Society for Surgery of the Alimentary Tract.

Jeffrey B. Matthews, M.D.

Charles J. Yeo, M.D.

Co-Editors, Journal of Gastrointestinal Surgery 